Review

\title{
Lycopene in Beverage Emulsions: Optimizing Formulation Design and Processing Effects for Enhanced Delivery
}

\author{
Erika Meroni ${ }^{1, *(1)}$ and Vassilios Raikos ${ }^{2}$ (1) \\ 1 Department of Food, Environmental and Nutritional Sciences (DeFENS), University of Milan, Via Celoria 2, \\ 20133 Milan, Italy \\ 2 Rowett Institute, University of Aberdeen, Aberdeen, Scotland AB25 2ZD, UK; v.raikos@abdn.ac.uk \\ * Correspondence: erika.meroni@unimi.it; Tel.: +39-02-503-16646
}

Received: 18 December 2017; Accepted: 17 January 2018; Published: 5 February 2018

\begin{abstract}
Lycopene is a desired ingredient in food formulations, yet its beneficial effects on human health remain largely underexploited due to its poor chemical stability and bioavailability. Oil-in-water emulsions may offer multiple advantages for the incorporation and delivery of this carotenoid species. Engineering and processing aspects for the development of emulsion-based delivery systems are of paramount importance for maintaining the structural integrity of lycopene. The selection of emulsifiers, $\mathrm{pH}$, temperature, oil phase, particle size, homogenization conditions and presence of other antioxidants are major determinants for enhancing lycopene stability and delivery from a food emulsion. Process and formulation optimization of the delivery system is product-specific and should be tailored accordingly. Further research is required to better understand the underlying mechanisms of lycopene absorption by the human digestive system.
\end{abstract}

Keywords: lycopene; emulsion; antioxidant; bioavailability; processing

\section{Introduction}

Lycopene was isolated for the first time by Hartsen (1873) from Tamus communis L. berries, and a few years later, Schunk (1903) gave its former name after showing that this pigment from tomato had a different absorption spectrum than carotenes from carrots [1]. Although, from a nutritional perspective, lycopene is not essential for life, it belongs to a group of compounds of immense biological importance known as phytochemicals. Phytochemicals have attracted much attention recently due to their documented effects on human health. Many epidemiological studies propose an inverse relationship between the consumption of lycopene and the development of chronic diseases [2]. Lycopene's main effect on human health is mediated through its strong antioxidant properties, which are demonstrated in a host of chemical reactions known to be implicated in carcinogenesis and atherogenesis [3].

The bioavailability of lycopene is a complex issue and depends on multiple factors. Firstly, lycopene due to its highly unsaturated hydrocarbon structure is susceptible to degradation via autooxidation or trans-cis isomerisation reactions [4]. The rate and extent of these degradation phenomena are dependent on many environmental factors, with the most important being temperature, light and oxygen [5]. In addition to processing and storage effects, lycopene's bioavailability is also limited because of its hydrophobic nature. In aqueous environments, lycopene tends to aggregate and forms crystals, which partly explains the low levels of this carotenoid detected in serum after a lycopene-rich meal [6]. This matrix effect may be ameliorated if lycopene is co-ingested with an oil-based food. Finally, other host-related factors such as genetic factors are considered important for the absorption of lycopene by the human digestive system, although these are still poorly understood. 
With increasing awareness of lycopene's beneficial effects on the prevention of chronic diseases, the food industry is keen on including this compound as functional ingredient in various formulations, including beverages. However, its incorporation in food products remains problematic due to its poor physical and chemical stability, usually derived from common processing and storage methods. Oil-in-water emulsions are considered effective carrier systems for the delivery of lipophilic bioactive ingredients [7]. Emulsion-based food systems confer protection against oxidation and chemical degradation of hydrophobic compounds, thus prolonging shelf-life and potentially also enhancing the bioaccessibility of the bioactive ingredient. The formulation and processing steps to develop such a delivery system are critical for the physicochemical properties of the product, which in turn affects its effectiveness as a delivery matrix.

The effects of food processing and storage on lycopene have been previously reviewed [3]. Although considerable research has been published on lycopene-containing emulsions and their properties, a review on this topic is currently lacking from the literature. This review aims to summarize and critically discuss the main findings related to emulsion design and processing with special focus on lycopene stability and bioaccessibility. Optimum formulations and processing conditions are presented for applications of lycopene as a functional ingredient in the food and drink industry.

\section{Lycopene as Functional Ingredient: Structure, Properties and Health Effects}

Lycopene is a natural pigment responsible for the red color of some fruits, such as tomato, watermelon, grapefruit, guava and papaya [8,9]. It belongs to the carotenoid family; specifically, to the class of carotenes, since it contains only carbon and hydrogen atoms. Lycopene is an aliphatic hydrocarbon and is characterized by a symmetric structure containing 11 conjugated and 2 non-conjugated double bonds arranged in a linear array, thus making it longer than other carotenoids. Due to its symmetrical planarity and the absence of a terminal beta ionone ring, it lacks pro-vitamin A activity $[10,11]$.

In nature, lycopene is mostly present in all-trans forms; however, isomerization to cis can occur in the presence of light, exposure to heat or by chemical reactions (for example during food processing or cooking) [12]. Theoretically, lycopene can exist in 2048 geometrical configurations, but only 72 cis-isomers of lycopene are structurally favorable (Figure 1). Cis-configuration is the most stable thermodynamically and best absorbed by humans, with $50 \%$ of the total lycopene in human plasma occurring as cis-lycopene. It has been hypothesized that cis-isomers are more bioavailable than all trans-lycopene because they are more rapidly taken up by bile acids micelles and consequently their absorption is facilitated. Moreover, cis-isomers are more soluble in lipophilic solutions and less prone to crystallization $[10,13]$.

Among the carotenoids, lycopene is predominant in human plasma. It has been detected at a concentration range between $0.4 \mu \mathrm{M}$ in North and Central Europe and up to $1.3 \mu \mathrm{M}$ in South Italy, hence lycopene levels are strongly related to dietary preferences [14]. Despite a significant gap of knowledge related to lycopene absorption and metabolism in human tissue, it has been demonstrated that lycopene accumulates unevenly in various tissues (liver, prostate gland, adipose, skin, lungs, and colon) and its concentration tends to always be higher than those of all other carotenoids. Its half-life in the human body varies from 2 to 33 days and depends on the levels of oxidative stress encountered $[15,16]$.

As humans are unable to synthesize lycopene, the diet is the only source of this component in blood and tissues. In contrast with other carotenoids, lycopene is available mainly from a limited list of foods. The major sources of lycopene in the western diet are tomato products; at least $85 \%$ of our dietary lycopene comes from both tomato fruits and tomato-based products like ketchup, juice and sauce $[17,18]$. 


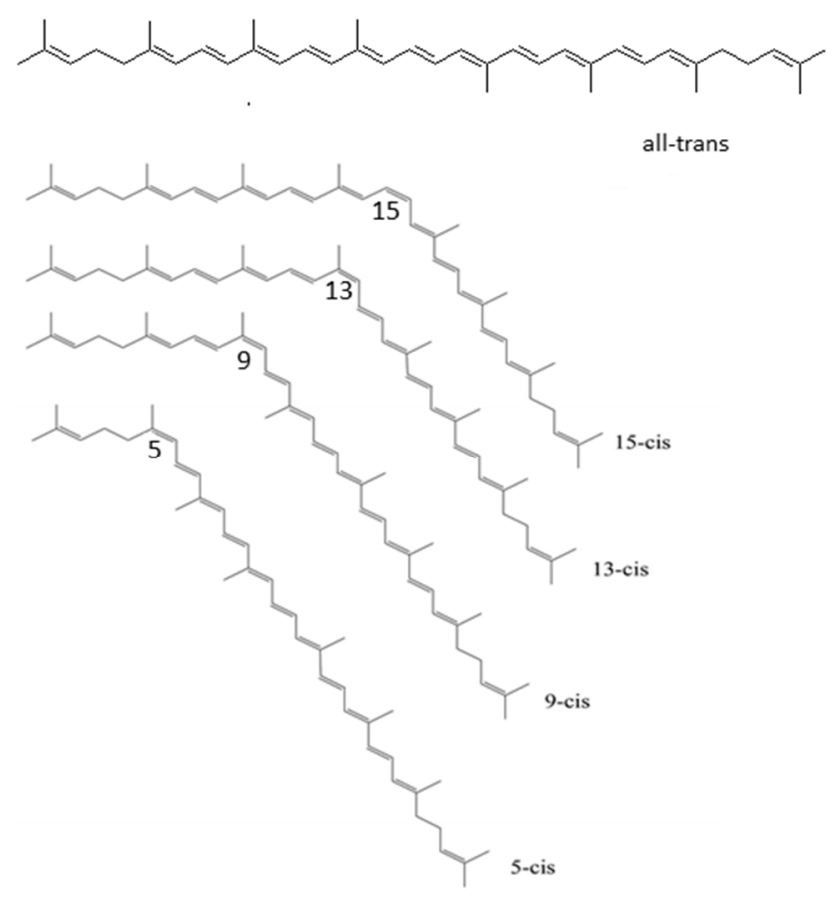

Figure 1. Structures of major lycopene isomers in tomato-based products and in human serum and tissues.

In recent years, there is increasing awareness of the beneficial effects associated with the consumption of lycopene-rich foods. Several studies have demonstrated that lycopene has a positive impact on human health due to its diverse biological properties. Firstly, it is a potent antioxidant, and has the most efficient singlet oxygen quenching capacity of the natural carotenoids (ten times more active than $\alpha$-tocopherol) $[19,20]$. The ability of lycopene to protect cells against oxidative damage is thought to be responsible for decreasing the risk of chronic diseases, including cardiovascular disease. By using different in vitro models (ECV304 endothelial cells, HUVECs, human macrophages) it has been demonstrated that lycopene is a potential antiatherogenic agent able to prevent oxidative stress and apoptosis. The hypothesized mechanism of action for lycopene in reducing the risk of coronary heart disease is mediated by preventing the oxidation of low-density lipoprotein (LDL) [21-23]. This assumption is supported by epidemiological data [24], but also by in vivo studies. In this respect, mice that had been fed an atherogenic diet containing $20 \%(w / w)$ lyophilized tomato powder showed reduced lipid peroxide levels in plasma compared to controls, while acetylcholine-induced vaso-relaxation was maintained at the normal levels [25]. Moreover, human intervention studies showed that daily consumption of lycopene-rich food products (tomato sauce or paste) could improve endothelial function and induce a significant reduction in oxidized LDL levels [26,27]. These results indicate that lycopene has a preventive effect on atherosclerosis by protecting plasma lipids from oxidation.

In addition to its antioxidant properties, lycopene may be further advantageous for human health by other biochemical mechanisms. It has been shown that lycopene can induce cell to cell communication; specifically, it stimulates gap junctional communication (GJC). Furthermore, lycopene enhances the expression of connexin 43 , a gene encoding for a major gap junction protein, and thereby upregulates GJC [28]. Given that upregulation of GJC is correlated with growth inhibition of precancerous cells, lycopene could also act as anticarcinogen $[29,30]$. Research findings showing an inverse relationship between cancer and lycopene are based on epidemiological [31], cell culture [2] and animal studies $[32,33]$. Specifically, lycopene was shown to be an inhibitor of endometrial, mammary and lung human cancer cell proliferation, and a suppressor of insulin-like growth factor-I [34]. 
A significant number of studies have demonstrated that a high lycopene intake was inversely related to the risk of prostate, bladder and breast cancer [35,36].

Although most of the research has focused on the protective effect of lycopene on cardiovascular and tumor diseases, it has recently been suggested that it could have other health implications. For instance, lycopene may provide protection against cell damage induced by ionizing radiation and therefore its supplementation could be used in mitigating the effects of a possible radiation accident, or in diminishing the negative impact of cancer radiotherapy [37-39].

\section{Stability of Lycopene in Emulsions: Formulation and Processing Implications}

Lycopene is susceptible to thermal and oxidative degradation during processing and storage. This is due to the fact that it is lipid-soluble and has a highly unsaturated structure. One way of protecting lycopene from degradation, while at the same time improving its bioavailability, is to incorporate it into the oil-phase of oil-in-water emulsions [40]. Although emulsions are effective systems for functional foods, both chemical and physical stability of lycopene in emulsion delivery systems may be problematic. Several studies have been carried out in this area, in order to understand the most important factors influencing the stability of lycopene in emulsion-based systems. Chemical degradation is significantly affected by a number of parameters; however, the most relevant are heat, oxygen and light. Different studies suggest that even if thermal processing increases the amount of cis-lycopene (by enhancing its isomerization), application of heat always decreases the content of total lycopene present in food. Moreover, the percentage of loss depends on the method of heating (drying, microwave, or baking) [11,16].

One of the first papers using oil-in-water emulsions for lycopene encapsulation was published by Ax and colleagues. They investigated the stability of lycopene under oxygen saturation or oxygen-free conditions. The results showed that higher temperatures were significantly and directly correlated to increasing lycopene losses, regardless of the exposure to oxygen. Interestingly, in the presence of oxygen, lycopene destabilization was about three times higher than under inert conditions. Therefore, total lycopene degradation could be reduced by flushing the emulsion with nitrogen gas [41]. In 2003, Ribeiro et al. confirmed the great influence of oxygen on lycopene degradation. However, they found that lycopene degradation was accelerated when oxygen was removed by flushing the system with nitrogen. Instead, using the enzyme glucose oxidase to completely exclude oxygen, led to a better stability [42]. An additional aspect highlighted by this research was that the chemical stability of lycopene strongly depends on the food systems, and emulsifiers may only have a minor impact, depending on the food systems in which they are applied. An emulsifier is an amphiphilic molecule that, during the emulsification process, facilitates the formation of smaller particles droplets, reduces the interfacial tension between the oil and the water phase, and prevents droplet coalescence by keeping the two phases mixed and stable [43]. The study by Ribeiro revealed that during storage, emulsifiers have a limited effect on the degradation of lycopene in water compared with orange juice and skimmed milk. Thus, in these experiments, the food systems play a more important role in lycopene stability than the investigated emulsifiers [42].

Given the relevance of emulsifiers in emulsion delivery systems, further studies have investigated their effect on lycopene stability in detail. In 2008, Boon et al. discovered that the formation of lipid hydroperoxides did not vary significantly among lycopene emulsions stabilized with different types of emulsifiers. Nevertheless, the emulsions stabilized with sodium dodecyl sulphate (SDS) showed a faster formation of hexanal, compared to others stabilized with dodecyltrimethylammonium bromide (DTAB) or lauryl ether (Brij 35). Hence, the great impact of the emulsion interfacial properties on lycopene oxidation and degradation was demonstrated. As negatively charged interfaces of emulsions droplets (SDS) were correlated with the fastest oxidation rates, the authors assumed that cationic transition metals could be promoting lycopene degradation. A likely mechanism is that cations may interact more rapidly with lycopene located in the droplet interior as they are strongly attracted to the emulsion surface [44]. In a later study by Nishino et al., the photostability 
of lycopene dispersions containing gum arabic, gum ghatti and polyglycerol monostearate ester was compared. Their results showed that the stability of lycopene in aqueous solution was influenced by the type and amount of emulsifier used. Specifically, the most stable was the one with polyglycerol monostearate ester, probably because when it is present at high concentrations, it forms a multilayered, emulsifier-adsorbing layer at the interface that prevents the contact between lycopene and dissolved oxygen [45]. More recently, Shariffa et al. investigated the specific effect of four different emulsifiers: Tween 80 , lecithin, sodium caseinate and gum arabic. They demonstrated that the emulsifier type significantly affects the physicochemical properties of the emulsions and is one of the most important factors to consider when producing a lycopene nanodispersion. It was shown that the size of lycopene droplets depends on the structure and the size of the emulsifier used. Comparing the four emulsifiers, the most stable systems were those with lecithin, having the smallest droplet size and the narrowest particle size distribution. On the other hand, sodium caseinate was the most effective emulsifier against lycopene degradation. Thus, despite its large size, sodium caseinate can be used to produce stable nano-emulsions with lycopene droplets having mean diameter less than $200 \mathrm{~nm}$. Instead, Tween 80 and gum arabic, were less capable to confer stability against lycopene degradation and droplet aggregation. Therefore, an emulsion-based system with the smallest particle size is not always the most stable, especially in the case of lycopene [46]. This finding has been confirmed by a recent paper that studied the physicochemical stability of lycopene-loaded emulsions stabilized by plant or dairy proteins. Once again, the capacity of sodium caseinate to stabilize an emulsion system was demonstrated. Both sodium caseinate and pea protein-stabilized emulsions were promising delivery vehicles, because they exhibited high chemical and physical stability after 14 days of storage [47].

Another factor that determines the stability of lycopene-emulsions is the type of oil used for emulsion formation. As demonstrated in the study by Boon et al., lycopene degradation was varied by using different oil carriers, and was in the order of stripped corn oil $>$ hexadecane $>$ corn oil. The fact that lycopene degraded faster in the stripped corn oil and hexadecane compared to corn oil implies that the antioxidants naturally present in corn oil (such as tocopherols), could play a protective role. It has been hypothesized that tocopherols may inhibit lycopene oxidation because they are oxidized prior to lycopene [44]. This theory is consistent with the findings reported previously by Ribeiro et al., which demonstrated that the stability of lycopene in dilute emulsions was improved when $\alpha$-tocopherol was incorporated in the oil phase, by inhibiting lycopene's degradation [42].

A significant body of literature investigated the formulation aspects of lycopene emulsions and assessed whether these could impact on its stability, in order to identify optimum recipes for manufacturing lycopene-loaded emulsion. Recently, two different formulations have been proposed considering several factors, including processing type (homogenization vs. evaporation), concentration of lycopene, type and quantity of emulsifiers and the amount of the oil-phase. According to Kim et al. The lycopene emulsion showing the highest stability was the one obtained after three homogenization cycles with $0.085 \mathrm{mg} / \mathrm{mL}$ of lycopene extract and $0.7 \mathrm{mg} / \mathrm{mL}$ of Tween 80 [48]. On the other hand, Shi et al. proposed an optimized microemulsion containing $0.2 \mathrm{~g} / 100 \mathrm{~g}(w / w)$ whey protein concentrate (WPC), $0.5 \mathrm{~g} / 100 \mathrm{~g}(w / w)$ high-methylester-pectin (HMP) and $5 \mathrm{~mL} / 100 \mathrm{~mL}$ oil phase fraction. This optimized lycopene-microemulsion was more stable to thermal treatment and changes of $\mathrm{pH}$, but was particularly sensitive to $\mathrm{NaCl}$ treatment [49].

In conclusion, it is evident that several parameters must be considered for the fabrication of lycopene emulsion-systems. Depending on the food application, it is important to take into account the synergistic effects of these factors, in order to identify the optimum conditions for enhanced chemical and physical stability of lycopene in an emulsion delivery system.

\section{Factors Affecting Bioaccessibility of Lycopene in Emulsions}

To exert a health benefit, lycopene needs to be bioavailable. This means that the bioactive compound must be absorbed in the human digestive tract, undergo metabolism, and become available in an active form at the site of action. Bioavailability of nutrients and non-nutrients depends on 
bioaccessibility. The term is used to describe the fraction of a compound that is released from the food matrix during digestion and is thereby made available for intestinal absorption (Figure 2) [50]. Bioaccessibility depends on numerous factors, such as the composition of the digested food matrix, the synergisms and antagonisms of the different food components, but also on physicochemical properties, such as $\mathrm{pH}$, temperature and texture of the matrix [51].

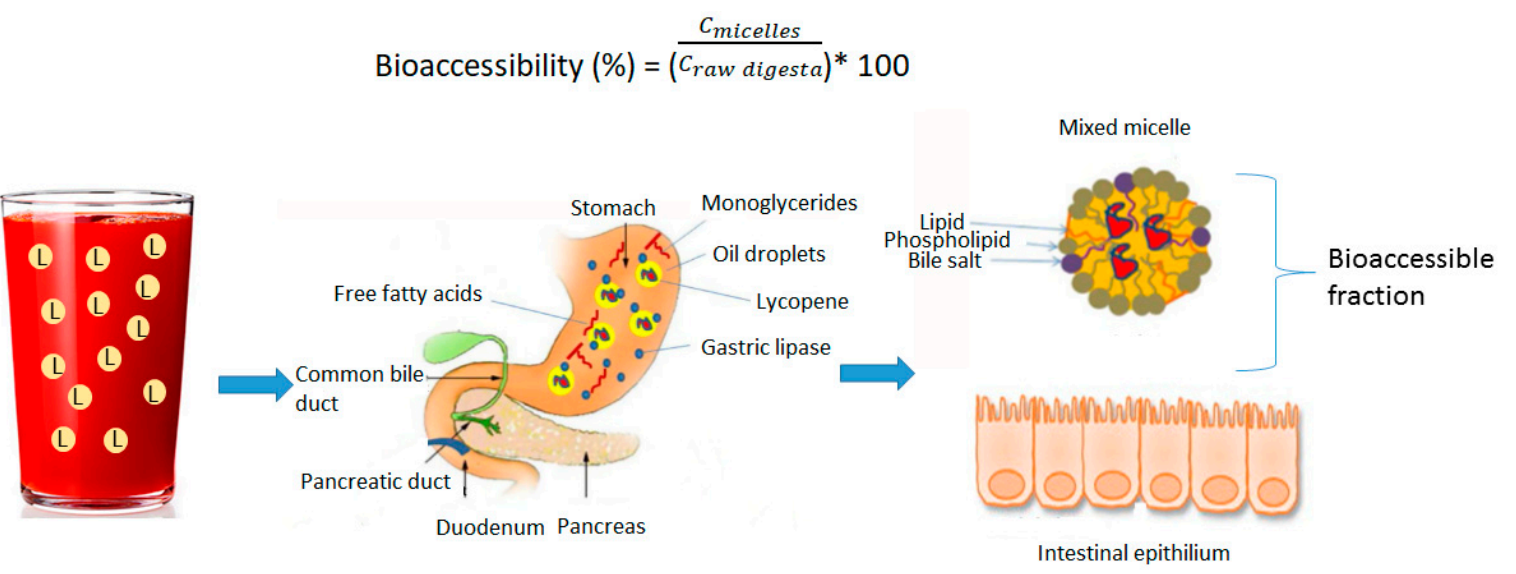

Figure 2. Overview of digestion process in the human gastrointestinal tract. Bioaccessibility refers to the amount of ingested lycopene released from the beverage emulsion that is potentially available for absorption by the enterocytes of the intestinal lumen.

Lycopene bioaccessibility from raw tomato products is relatively low, and ranges between $0.1 \%$ and 3\% [52]. The low lycopene bioaccessibility (compared to other carotenes) is attributed to the low solubility of the former in dietary lipids and to its entrapment in the fibrous cellular network [53]. Food processing may improve the bioaccessibility (and bioavailability) of lycopene by breaking down cell walls and facilitating the weakening of the bonding forces between lycopene and plant tissue matrix [3]. Additionally, the chemical form of lycopene may be altered from trans isomers to cis isomers by the temperature changes involved in processing and therefore enhancing absorption in the body [54]. Finally, lycopene digestion and absorption may be further enhanced in the presence of oil, since the latter would enhance the solubilization efficiency of the carotenoid into mixed micelles [55].

Most of the published data on lycopene bioaccessibility from emulsion-based systems is derived from in vitro studies, which adopt a simulated gastric and intestinal model and determine the fraction of solubilized lycopene in mixed micelles compared to the amount of lycopene in raw digesta. Recent studies indicate that nanoemulsions fabricated with lycopene-enriched tomato extract show potential for increasing lycopene bioaccessibility [56]. The droplet size $(d)$ of the nanoemulsions is critical for increasing bioaccessibility of lycopene and optimum results were reported for $d<100 \mathrm{~nm}$. Similar findings were reported by another study which investigated the potential of excipient emulsions to increase lycopene bioaccessibility from tomato juice [57]. The term "excipient emulsions" is used to describe foods that lack any bioactive components but may promote the bioavailability of co-ingested bioactive agents. This study revealed that lycopene bioaccessibility from tomato products was highest $(12.5 \%)$ when co-ingested with excipient emulsions containing small particles $(d<200 \mathrm{~nm})$. The effect of particle size on the lycopene bioaccessibility is related to the increased surface area of the small droplets. This facilitates the interaction between the droplet surface and digestive components (enzymes, bile salts, phospholipids, cholesterol) and results in complete digestion under simulated gastrointestinal conditions and subsequent incorporation of lycopene within the micelle fraction. An additional factor that may affect lycopene bioavailability from emulsions is the type of oil used as dispersed phase. Animal studies have demonstrated that lycopene recovery was $6 \%$ from olive oil emulsions but only $2.5 \%$ when corn oil was used [58]. A few possible mechanisms have been suggested to explain the low lycopene bioaccessibility from emulsions containing corn oil, which mainly relate to the high levels 
of polyunsaturated fatty acids (PUFA). Firstly, PUFAs are susceptible to oxidation reactions and may promote oxidation of lycopene in the intestinal chime. Secondly, the size of mixed micelles containing PUFAs may be larger, which in turn can slow down their diffusion through the unstirred water layer adjacent to the enterocyte and reduces their uptake at the intestinal level [59].

\section{Conclusions and Future Trends}

The inclusion of lycopene in food formulations is desirable, since epidemiological studies suggest a beneficial role in chronic disease prevention. Its utilization as a functional ingredient is hindered by the lack of chemical stability and poor absorption at the digestive tract. Current research indicates that lycopene stability largely depends on the food system, and that processing may increase its bioavailability. The fabrication of emulsions for delivering lycopene could be a promising option for the food and beverage industry. However, the engineering aspects need to be carefully designed for optimum performance. The selection of specific emulsifiers at the droplet interface and the presence of tocopherols improves lycopene stability in oil-in-water emulsions. Additionally, droplet size and the type of oil used for emulsion formation may be critical for absorption. There seems to be a gap in our knowledge of lycopene absorption and metabolism from complex food systems due to the limited number of human studies and the lack of accessible biomarkers. This results in discrepancies between data and limited understanding of the intracellular mechanisms involved in the potent health benefits of this carotenoid species.

Acknowledgments: This work is part of the Strategic Research Programme 2016-2021 and is funded by the Scottish Government's Rural and Environment Science and Analytical Services Division (RESAS).

Author Contributions: Both authors contributed equally to the writing of the manuscript.

Conflicts of Interest: The authors declare no conflict of interest.

\section{References}

1. Vogele, A.C. Effect of environmental factors upon the color of the tomato and the watermelon. Plant Physiol. 1937, 12, 929-955. [CrossRef] [PubMed]

2. Rao, A.V.; Agarwal, S. Role of lycopene as antioxidant carotenoid in the prevention of chronic diseases: A review. Nutr. Res. 1999, 19, 305-323. [CrossRef]

3. Xianquan, S.; Shi, J.; Kakuda, Y.; Yueming, J. Stability of lycopene during food processing and storage. J. Med. Food 2005, 8, 413-422. [CrossRef] [PubMed]

4. Shi, J. Lycopene in tomatoes: Chemical and physical properties affected by food processing. Crit. Rev. Food Sci. Nutr. 2000, 40, 1-42. [CrossRef] [PubMed]

5. Nguyen, M.L.; Schwartz, S.J. Lycopene stability during food processing. Exp. Biol. Med. 1998, 218, 101-105. [CrossRef]

6. Zumbrunn, A.; Uebelhart, P.; Eugster, C.H. HPLC of carotenes with y-end groups and (Z)-configuration at terminal conjugated double bonds, isolation of (5Z)-lycopene from tomatoes. Helv. Chim. Acta 1985, 68, 1540-1542. [CrossRef]

7. Raikos, V.; Ranawana, V. Designing emulsion droplets of foods and beverages to enhance delivery of lipophilic bioactive components-A review of recent advances. Int. J. Food Sci. Technol. 2017, 52, 68-80. [CrossRef]

8. Rao, A.V.; Agarwal, S. Role of antioxidant lycopene in cancer and heart disease. J. Am. Coll. Nutr. 2000, 19, 563-569. [CrossRef] [PubMed]

9. Stahl, W.; Sies, H. Lycopene: A biologically important carotenoid for humans? Arch. Biochem. Biophs. 1996, 336, 1-9. [CrossRef] [PubMed]

10. Britton, G. Structure and properties of carotenoids in relation to function. FASEB J. 1995, 9, 1551-1558. [CrossRef] [PubMed]

11. Shi, J.; Maguer, L.M. Lycopene in tomatoes: Chemical and physical properties affected by food processing. Crit. Rev. Biotechnol. 2000, 20, 293-334. [CrossRef] [PubMed] 
12. Tonucci, L.H.; Holden, J.M.; Beecher, G.R.; Khachik, F.; Davis, C.S.; Generose, M.G. Carotenoid content of thermally processed tomato-based food products. J. Agric. Food Chem. 1995, 43, 579-586. [CrossRef]

13. Boileau, T.W.; Boileau, A.C.; Erdman, J.W. Bioavailability of all-trans and cis-isomers of licopene. Exp. Biol. Med. 2002, 227, 914-919. [CrossRef]

14. Jenab, M.; Ferrari, P.; Mazuir, M.; Tjonneland, A.; Clavel-Chapelon, F.; Linseisen, J.; Trichopoulou, A.; Tumino, R.; Bueno-de-Mesquita, H.B.; Lund, E.; et al. European prospective investigation into cancer and nutrition (EPIC) study. Variations in lycopene blood levels and tomato consumption across European countries based on the european prospective investigation into cancer and nutrition (EPIC) study. J. Nutr. 2005, 135, 2032S-2036S. [CrossRef] [PubMed]

15. Rao, A.V.; Agarwal, S. Bioavailability and in vivo antioxidant properties of lycopene from tomato products and their possible role in the prevention of cancer. Nutr. Cancer 1998, 31, 199-203. [CrossRef] [PubMed]

16. Srivastava, S.; Srivastava, A.K. Lycopene; chemistry, biosynthesis, metabolism and degradation under various abiotic parameters. J. Food Sci. Technol. 2015, 52, 41-53. [CrossRef]

17. Bramley, P.M. Is lycopene beneficial to human health? Phytochemistry 2000, 54, 233-236. [CrossRef]

18. Kun, Y.; Lule, U.S.; Xiao-Lin, D. Lycopene: Its Properties and Relationship to Human Health. Food Rev. Int. 2006, 22, 309-333. [CrossRef]

19. Sundquist, A.R.; Briviba, K.; Sies, H. Singlet oxygen quenching by carotenoids. Methods Enzymol. 1994, 234, 384-388. [PubMed]

20. Müller, L.; Caris-Veyrat, C.; Lowe, G.; Böhm, V. Lycopene and its antioxidant role in the prevention of cardiovascular diseases-A critical review. Crit. Rev. Food Sci. 2016, 56, 1868-1879. [CrossRef] [PubMed]

21. Tang, X.; Yang, X.; Peng, Y.; Lin, J. Protective effects of licopene against $\mathrm{H}_{2} \mathrm{O}_{2}$-induced oxidative injury and apoptosis in human endothelial cells. Cardiovasc. Drugs Ther. 2009, 23, 439-448. [CrossRef] [PubMed]

22. Hung, C.F.; Huang, T.F.; Chen, B.H.; Shieh, J.M.; Wu, P.H.; Wu, W.B. Lycopene inhibits TNF-alpha-induced endothelial ICAM-1 expression and monocyte-endothelial adhesion. Eur. J. Pharmacol. 2008, 586, $275-282$. [CrossRef] [PubMed]

23. Palozza, P.; Simone, R.; Catalano, A.; Boninsegna, A.; Bohm, V.; Frohlich, K.; Mele, M.C.; Monego, G.; Ranelletti, F.O. Lycopene prevents 7-ketocholesterol-induced oxidative stress, cell cycle arrest and apoptosis in human macrophages. J. Nutr. Biochem. 2010, 21, 34-46. [CrossRef] [PubMed]

24. Suganuma, H.; Inakuma, T. Protective effect of dietary tomato against endothelial dysfunction in hypercholesterolemic mice. Biosci. Biotechnol. Biochem. 1999, 63, 78-82. [CrossRef] [PubMed]

25. Abete, I.; Perez-Cornago, A.; Navas-Carretero, S.; Bondia-Pons, I.; Zulet, M.A.; Martinez, J.A. A regular lycopene enriched tomato sauce consumption influences antioxidant status of healthy young-subjects: A crossover study. J. Funct. Foods 2013, 5, 28-35. [CrossRef]

26. Xaplanteris, P.; Vlachopoulos, C.; Pietri, P.; Terentes-Printzios, D.; Kardara, D.; Alexopoulos, N.; Aznaouridis, K.; Miliou, A.; Stefanadis, C. Tomato paste supplementation improves endothelial dynamics and reduces plasma total oxidative status in healthy subjects. Nutr. Res. 2012, 32, 390-394. [CrossRef] [PubMed]

27. Stahl, W.; von Laar, J.; Martin, H.D.; Emmerich, T.; Sies, H. Stimulation of gap junctional communication: Comparison of acyclo-retinoic acid and lycopene. Arch Biochem. Biophys. 2000, 373, 271-274. [CrossRef] [PubMed]

28. Rao, A.V. Lycopene, tomatoes, and the prevention of coronary heart disease. Exp. Biol. Med. 2002, 227, 908-913. [CrossRef]

29. Tapiero, H.; Townsend, D.M.; Tew, K.D. The role of carotenoids in the prevention of human pathologies. Biomed. Pharmacother. 2004, 58, 100-110. [CrossRef] [PubMed]

30. Giovannucci, E.; Ascherio, A.; Rimm, E.B.; Stampfer, M.J.; Colditz, G.A.; Willet, W.C. Intake of carotenoids and retinol in relation to risk of prostate cancer. J. Natl. Cancer Inst. 1995, 87, 1767-1776. [CrossRef] [PubMed]

31. Countryman, C.; Bankson, D.; Collins, S.; Mar, B.; Lin, W. Lycopene inhibits the growth of the HL-60 promyelocytic leukemia cell line. Clin. Chem. 1991, 37, 1056.

32. Nagasawa, H.; Mitamura, T.; Sakamoto, S.; Yamamoto, K. Effects of lycopene on spontaneous mammary tumour development in SHN virgin mice. Anticancer Res. 1995, 15, 1173-1178. [PubMed]

33. Kobayashi, T.; Iijima, K.; Mitamura, T.; Toriizuka, K.; Cyong, J.C.; Nagasawa, H. Effects of lycopene, a carotenoid, on intrathymic $\mathrm{T}$ cell differentiation and peripheral CD4/CD8 ratio in a high mammary tumor strain of SHN retired mice. Anticancer Drugs 1996, 7, 195-198. [CrossRef] [PubMed] 
34. Levy, J.; Bosin, E.; Feldmen, B.; Giat, Y.; Miinster, A.; Danilenko, M.; Sharoni, Y. Lycopene is a more potent inhibitor of human cancer cell proliferation than either $\alpha$-carotene or $\beta$-carotene. Nutr. Cancer 1995, 24, 257-266. [CrossRef] [PubMed]

35. Helzlsouer, K.J.; Comstock, G.W.; Morris, J.S. Selenium, lycopene, $\alpha$-tocopherol, $\beta$-carotene, retinol and subsequent bladder cancer. Cancer Res. 1989, 49, 6144-6148. [PubMed]

36. Potischman, N.; McCulloch, C.E.; Byers, T.; Nemoto, T.; Stubbe, N.; Milch, R. Breast cancer and dietary and plasma concentrations of carotenoids and vitamin A. Am. J. Clin. Nutr. 1990, 52, 909-915. [CrossRef] [PubMed]

37. Andic, F.; Garipagaoglu, M.; Yurdakonar, E.; Tuncel, N.; Kucuk, O. Lycopene in the prevention of gastrointestinal toxicity of radiotherapy. Nutr. Cancer 2009, 61, 784-788. [CrossRef] [PubMed]

38. Cavusoglu, K.; Yalcin, E. Radioprotective effect of lycopene on chromosomal aberrations (CAs) induced by gamma radiation in human lymphocytes. J. Environ. Biol. 2009, 30, 113-117. [PubMed]

39. Gajowik, A.; Dobrzyńska, M.M. Lycopene-antioxidant with radioprotective and anticancer properties. A review. Roczniki Państwowego Zakładu Higieny 2014, 65, 263-271. [PubMed]

40. McClements, D.J.; Decker, E.A.; Park, Y.; Weiss, J. Strctural design principles for delivery of bioactive components in nutraceuticals and functional foods. Crit. Rev. Food Sci. Nutr. 2009, 49, 577-606. [CrossRef] [PubMed]

41. Ax, K.; Mayer-Miebach, E.; Link, B.; Schuchmann, H.; Schubert, H. Stability of lycopene in oil-in-water emulsions. Eng. Life Sci. 2003, 4, 199-201. [CrossRef]

42. Ribeiro, H.S.; Ax, K.; Shubert, H. Stability of lycopene emulsions in food systems. J. Food Sci. 2003, 68, 2730-2734. [CrossRef]

43. Berton-Carabin, C.C.; Ropers, M.H.; Genot, C. Lipid Oxidation in Oil-in-Water Emulsions: Involvement of the Interfacial Layer. Compr. Rev. Food Sci. Food Saf. 2014, 13, 945-977. [CrossRef]

44. Boon, C.S.; Xu, Z.; Yue, X.; McClements, D.J.; Weiss, J.; Decker, E.A. Factors affecting lycopene oxidation in oil-in-water emulsions. J. Agric. Food Chem. 2008, 56, 1408-1414. [CrossRef] [PubMed]

45. Nishino, M.; Sakata, M.; Murata, Y.; Nakamura, Y. Effects of emulsifiers on the photostability of lycopene. Food Sci. Technol. Res. 2013, 19, 983-987. [CrossRef]

46. Shariffa, Y.N.; Tan, T.B.; Uthumporn, U.; Abas, F.; Mirhosseini, H.; Nehdi, I.A.; Wang, Y.H.; Tan, C.P. Producing a lycopene nanodispersion: Formulation development and the effects of high pressure homogenization. Food Res. Int. 2017, 101, 165-172. [CrossRef] [PubMed]

47. Ho, K.K.H.Y.; Schroën, K.; Berton-Carabin, C.C.; San Martín-González, M.F.; Kacie, K.H.Y. Physicochemical stability of lycopene-loaded emulsions stabilized by plant or dairy proteins. Food Struct. 2017, 12, $34-42$. [CrossRef]

48. Kim, S.O.; Ha, T.V.; Choi, Y.J.; Ko, S. Optimization of homogenization-evaporation process for lycopene nanoemulsion production and its beverage applications. J. Food Sci. 2014, 79, N1604-10. [CrossRef] [PubMed]

49. Shi, J.; Xue, S.J.; Wang, B.; Wang, W.L.; Ye, X.Q.; Quek, S.Y. Optimization of formulation and influence of environmental stresses on stability of lycopene-microemulsion. Food Sci. Technol. 2015, 60, 999-1008. [CrossRef]

50. Saura-Calixto, F.; Serrano, J.; Goñi, I. Intake and bioaccessibility of total polyphenols in a whole diet. Food Chem. 2007, 101, 492-501. [CrossRef]

51. Neilson, A.P.; Ferruzzi, M.G. Influence of formulation and processing on absorption and metabolism of flavan-3-ols from tea and cocoa. Annu. Rev. Food Sci. Technol. 2011, 2, 125-151. [CrossRef] [PubMed]

52. Stahl, W.; Sies, H. Uptake of lycopene and its geometrical isomers is greater from heat-processed than from unprocessed tomato juice in humans. J. Nutr. 1992, 122, 2161-2166. [CrossRef] [PubMed]

53. Svelander, C.A.; Lopez-Sanchez, P.; Pudney, P.D.A.; Schumm, S.; Alminger, M.A.G. High pressure homogenisation increases the in vitro bioaccessibility of $\alpha$ - and $\beta$-carotene but not of lycopene in tomato emulsions. J. Food Sci. 2011, 76, H215-H225. [CrossRef] [PubMed]

54. Reboul, E.; Richelle, M.; Perrot, E.; Desmoulins-Malezet, C.; Pirisi, V.; Borel, P. Bioaccessibility of carotenoids and vitamin E from their main dietary sources. J. Agric. Food Chem. 2006, 54, 8749-8755. [CrossRef] [PubMed]

55. Colle, I.J.P.; Van Buggenhout, S.; Lemmens, L.; Van Loey, A.M.; Hendrickx, M.E. The type and quantity of lipids present during digestion influence the in vitro bioaccessibility of lycopene from raw tomato pulp. Food Res. Int. 2012, 45, 250-255. [CrossRef] 
56. Ha, T.V.A.; Kim, S.; Choi, Y.; Kwak, H.-S.; Lee, S.J.; Wen, J.; Oey, I.; Ko, S. Antioxidant activity and bioaccessibility of size-different nanoemulsions for lycopene-enriched tomato extract. Food Chem. 2015, 178, 115-121. [CrossRef] [PubMed]

57. Salvia-Trujillo, S.; McClements, D.J. Enhancement of lycopene bioaccessibility from tomato juice using excipient emulsions: Influence of lipid droplet size. Food Chem. 2016, 201, 295-304. [CrossRef] [PubMed]

58. Clark, R.M.; Yao, L.; She, L.; Furr, H.C.A. Comparison of lycopene and astaxanthin absorption from corn oil and olive oil emulsions. Lipids 2000, 35, 803-806. [CrossRef] [PubMed]

59. Hollander, D.; Ruble, P.E., Jr. Beta-Carotene Absorption: Bile, Fatty Acid, pH, and Flow Rate Effects on Transport. Am. J. Physiol. 1978, 235, E686-E691. [CrossRef] [PubMed]

C 2018 by the authors. Licensee MDPI, Basel, Switzerland. This article is an open access article distributed under the terms and conditions of the Creative Commons Attribution (CC BY) license (http://creativecommons.org/licenses/by/4.0/). 